\title{
Study of transitory phenomena at connecting the capacitive loads to an AC power source
}

\author{
Titu Niculescu, Marius Marcu, Florin-Gabriel Popescu* \\ Department of Control Engineering, Computers, Electrical Engineering and Power Engineering, University of Petrosani \\ *Corresponding author E-mail: floringabriel82@yahoo.com
}

Copyright $\odot 2015$ Florin-Gabriel Popescu et al. This is an open access article distributed under the Creative Commons Attribution License, which permits unrestricted use, distribution, and reproduction in any medium, provided the original work is properly cited.

\begin{abstract}
This paper presents a new and a modern method for study the inductive-capacitive circuits which are connected to an AC power source, using modern methods based on digital technology and software used in engineering applications. The capacitive circuits which are switched on an AC power source at the initial moment are presented below. We can determine the capacitor current variation forms, the capacitor voltage in a transient regime by using virtual mediums, in two different regimes: the oscillating regime and the-periodic regime. Each presented case contains an analytical presentation of the phenomenon, but it also contains the diagrams of current and voltage capacitors. The diagrams were obtained by two methods, which use MATLAB package. These diagrams are compared with experimental measurements obtained with a data-acquisition system produced by National Instruments using LABVIEW software.
\end{abstract}

Keywords: Capacitive Circuit; Data's Acquisition; Diagrams; Differential Equation; Labview; Simulation Model; Simulink.

\section{Introduction}

We can consider a RLC series circuit with concentrated parameters, which will be connected to an AC power source. We can meet this situation in practice, in case we want to connect to AC power source electrical equipment which includes capacitors. In this case can occur overvoltage or over currents during transient regime, which can cause problems system sizing. The circuit inductivity forms with the capacitors an oscillating circuit (Fig.1).

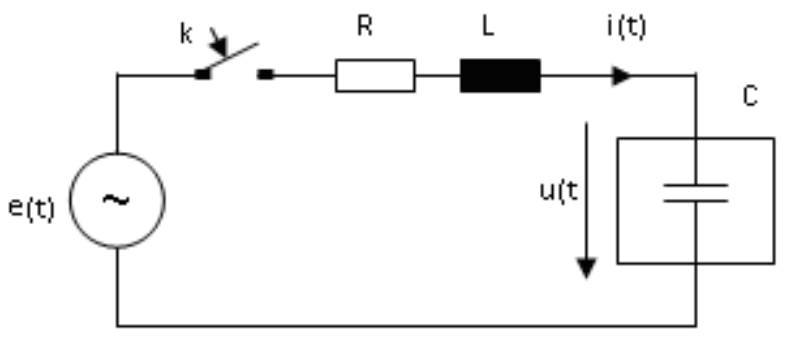

Fig. 1: Capacitor Connecting to an AC Voltage Source

The differential equation for transitory phenomena is presented below, where " $u(t)$ " is the capacitor voltage.

$L C \frac{d^{2} u(t)}{d t^{2}}+R C \frac{d u(t)}{d t}+u(t)=U_{m} \sin (\omega t+\psi)$

Where $\Psi$ is the initial phase of voltage when the circuit was connected. 


\section{Theoretical considerations}

\subsection{The oscillatory regime}

This event is known in the scientific literature as an oscillating regime. If we consider the R resistance of a circuit very small, the Laplace's method applied to this circuit conducts to the following solution [4]:

$$
u(t)=\frac{U_{m} \sin \left(\omega t+\psi-\phi_{1}\right)}{C \omega \sqrt{R^{2}+\left(\frac{1}{\omega C}-L \omega\right)^{2}}}+\frac{D U_{m} e^{-\delta t}}{2 L C \omega_{e}^{2}} \sin \left(\omega_{e} t-\gamma\right)
$$

Where $\delta$ is a dumping factor?

$$
\delta=\frac{R}{2 L}
$$

And $\omega_{0}$ is the resonance angular frequency of the circuit:

$$
\omega_{0}=\frac{1}{\sqrt{L C}}
$$

We also used the following notations:

$$
\begin{aligned}
& \omega_{e}=\sqrt{\omega_{0}^{2}-\delta^{2}} \\
& D=\sqrt{A^{2}+B^{2}-2 A B \cos (\beta-\alpha)} \\
& \operatorname{tg} \gamma=\frac{A \sin \alpha-B \sin \beta}{A \cos \alpha-B \cos \beta} \\
& \alpha=\phi_{3}+\psi ; \quad \beta=\phi_{2}-\psi \\
& \phi_{1}=\operatorname{arctg} \frac{2 \omega \delta}{\omega_{0}^{2}-\omega^{2}} \\
& \phi_{2}=\operatorname{arctg} \frac{\delta}{\omega_{e}-\omega} \\
& \phi_{3}=\operatorname{arctg} \frac{\delta}{\omega_{e}+\omega} \\
& A=\frac{\sqrt{\left(1-\frac{\omega}{\omega_{e}}\right)^{2}+\left(\frac{\delta}{\omega_{e}}\right)^{2}}}{\sqrt{\left(1+\frac{\omega}{\omega_{e}}\right)^{2}+\left(\frac{\delta}{\omega_{e}}\right)^{2}}} \\
& B_{e}
\end{aligned}
$$

It is noticed that the capacitors' voltage at its terminals contain a periodic component and a damped oscillatory component, which is canceled after a while from the connection moment. The solution for capacitor current results from expression (2) [4]:

$$
i=I_{m} \cos \left(\omega t+\psi-\phi_{1}\right)+\frac{D U_{m} e^{-\delta t}}{2 \omega_{e} L} \cdot\left[\cos \left(\omega_{e} t-\gamma\right)-\frac{\delta}{\omega_{e}} \sin \left(\omega_{e} t-\gamma\right)\right]
$$


Where:

$$
I_{m}=\frac{U_{m}}{\sqrt{R^{2}+\left(\frac{1}{\omega C}-\omega L\right)^{2}}}
$$

The current circuit contains also a periodic component and a damped oscillatory component, which disappears after a while from the connection moment.

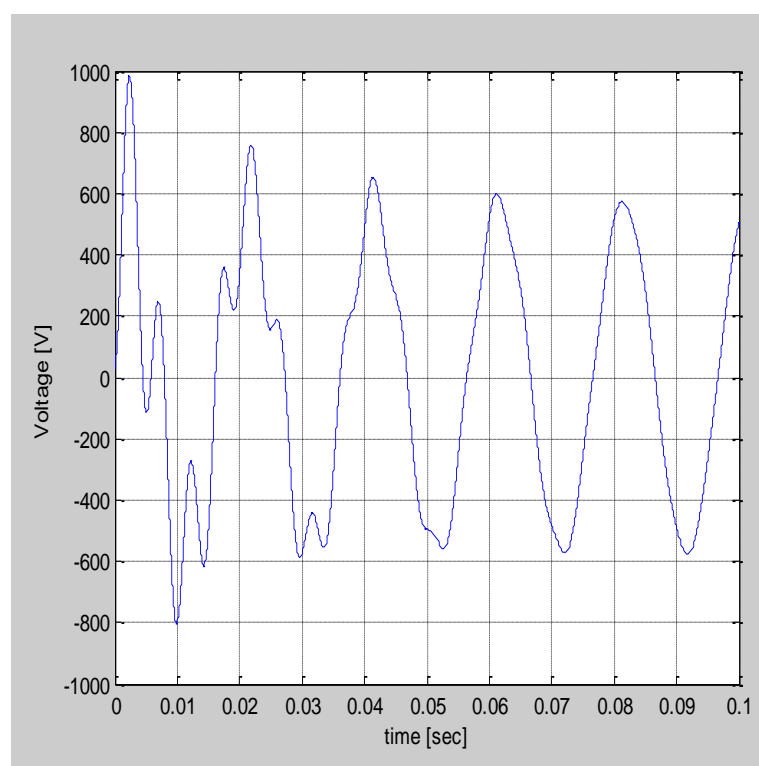

Fig. 2: Capacitor Voltage Diagram in the Oscillatory Regime

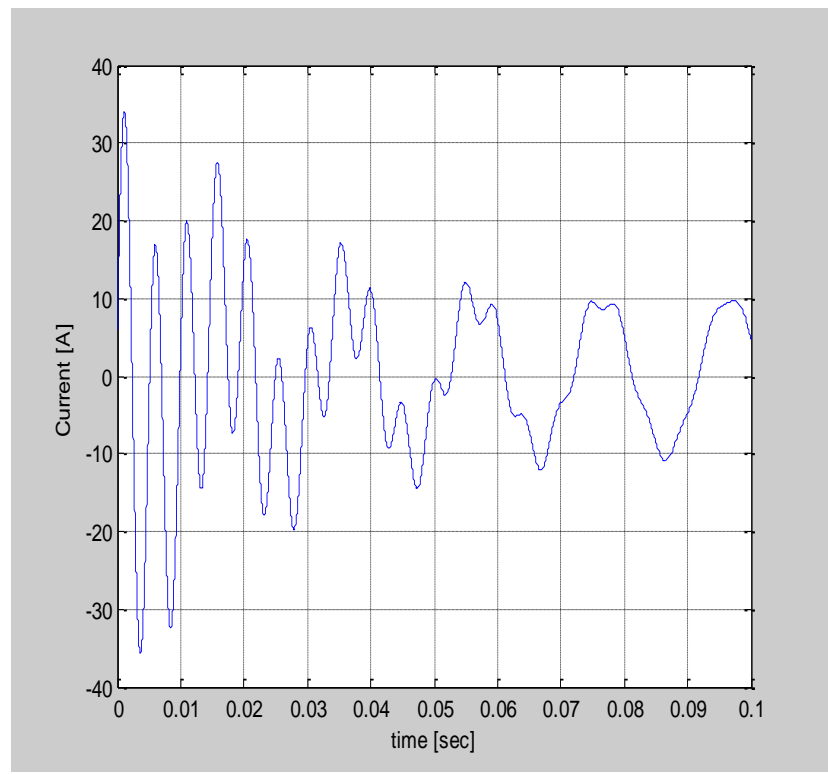

Fig. 3: Capacitor Current Diagram in the Oscillatory Regime

Diagrams from Fig.2 and Fig.3 are based on analytical expressions (2) and (14), and are plotted for the following value of electric circuit parameters, in MATLAB space by programing:

$\mathrm{U}_{\mathrm{ef}}=380[\mathrm{~V}] ; \mathrm{R}=1[\Omega] ; \mathrm{L}=12[\mathrm{mH}] ; \mathrm{C}=50[\mu \mathrm{F}] ; \mathrm{F}=50[\mathrm{~Hz}] ; \Psi=1.1[\mathrm{rad}]$.

\subsection{The aperiodic regime}

We consider that the resistance $\mathrm{R}$ is very big $\left(\delta>\omega_{0}\right)$. This situation is known as an aperiodic regime [4]. In this case:

$\omega_{e}=\sqrt{\delta^{2}-\omega_{0}^{2}}$

The original solution for equation (1) in this situation is [3]:

$u(t)=\frac{U_{m} \sin \left(\omega t+\psi-\phi_{1}\right)}{C \omega \sqrt{R^{2}+\left(\frac{1}{C \omega}-L \omega\right)^{2}}}+\frac{U_{m}}{2} \cdot \frac{\omega_{0}^{2}}{\omega_{e}} \cdot\left[\frac{e^{-\left(\delta-\omega_{e}\right) t} \sin \left(\phi_{2}-\psi\right)}{\sqrt{\left(\omega_{e}-\delta\right)^{2}+\omega^{2}}}-\frac{e^{-\left(\delta+\omega_{e}\right) t} \sin \left(\phi_{3}-\psi\right)}{\sqrt{\left(\omega_{e}+\delta\right)^{2}+\omega^{2}}}\right]$

In the expression that gives the instantaneous voltage in this regime, have made notations:

$\phi_{1}=\operatorname{arctg} \frac{2 \delta \omega}{\omega_{0}^{2}-\omega^{2}}$

$\phi_{2}=\operatorname{arctg} \frac{\omega}{\delta-\omega_{e}}$

$\phi_{3}=\operatorname{arctg} \frac{\omega}{\omega_{e}+\delta}$

Based on expression (17) is obtained the current expression in the aperiodic regime [4]: 


$$
i=I_{m} \cos \left(\omega t+\psi-\phi_{1}\right)+\frac{U_{m}}{2 \omega_{e} L}\left[\frac{\left(\delta+\omega_{e}\right) \sin \left(\phi_{3}-\psi\right) \cdot e^{-\left(\delta-\omega_{e}\right) t}}{\sqrt{\left(\omega_{e}+\delta\right)^{2}+\omega^{2}}}--\frac{\left(\delta-\omega_{e}\right) \sin \left(\phi_{2}-\psi\right) \cdot e^{-\left(\delta-\omega_{e}\right) t}}{\sqrt{\left(\omega_{e}-\delta\right)^{2}+\omega^{2}}}\right]
$$

Where $I_{m}$ is given by (15). Expressions (17) and (21) give the MATLAB diagrams in the aperiodic regime from Fig.4 and Fig.5. These diagrams were obtained for the following value of input parameters:

$\mathrm{U}_{\mathrm{ef}}=240[\mathrm{~V}] ; \mathrm{R}=15[\Omega] ; \mathrm{L}=12[\mathrm{mH}] ; \mathrm{C}=50[\mu \mathrm{F}] ; \mathrm{F}=50[\mathrm{~Hz}] ; \Psi=1.1[\mathrm{rad}]$.

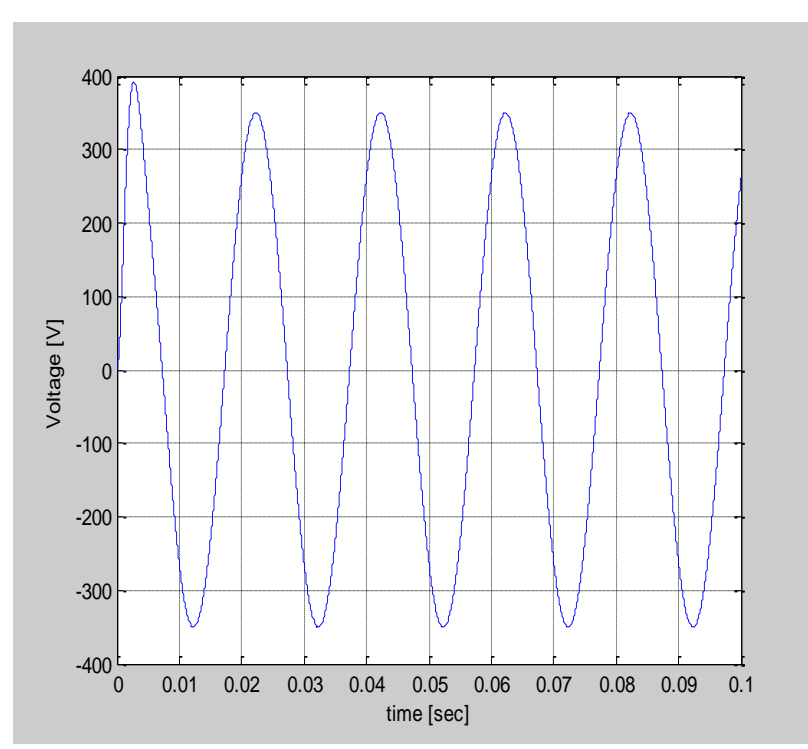

Fig. 4: Capacitor Voltage Diagram in the A-Periodic Regime

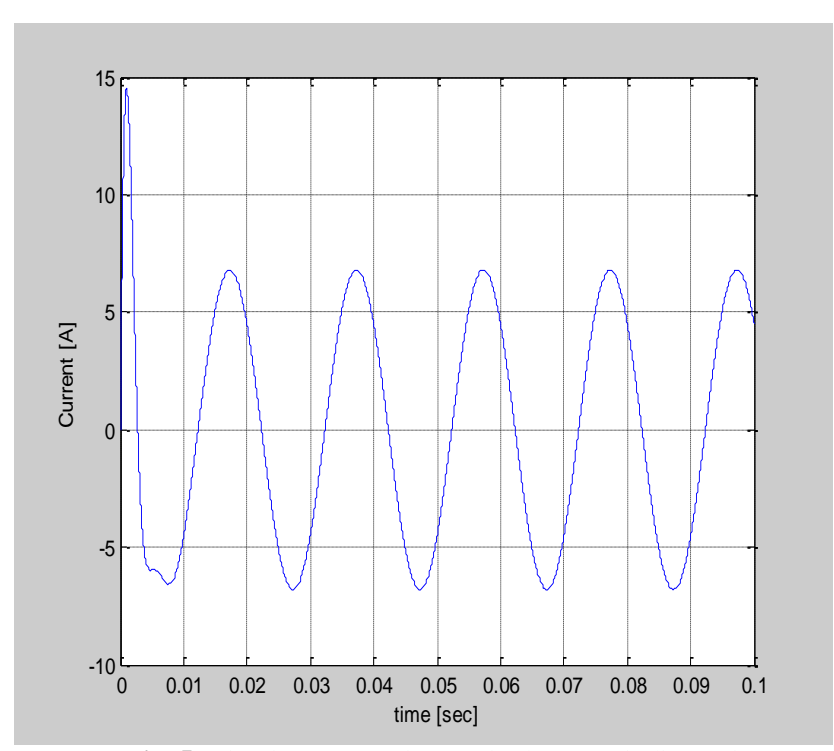

Fig. 5: Circuit Current Diagram in the A-Periodic Regime

\section{Simulink model of capacitive circuit}

The SIMULINK model for capacitor current in the-periodic regime was made in agreement with the mathematics form (1). This model allows the generation the capacitor current and voltage diagrams for all regimes (Fig.6).

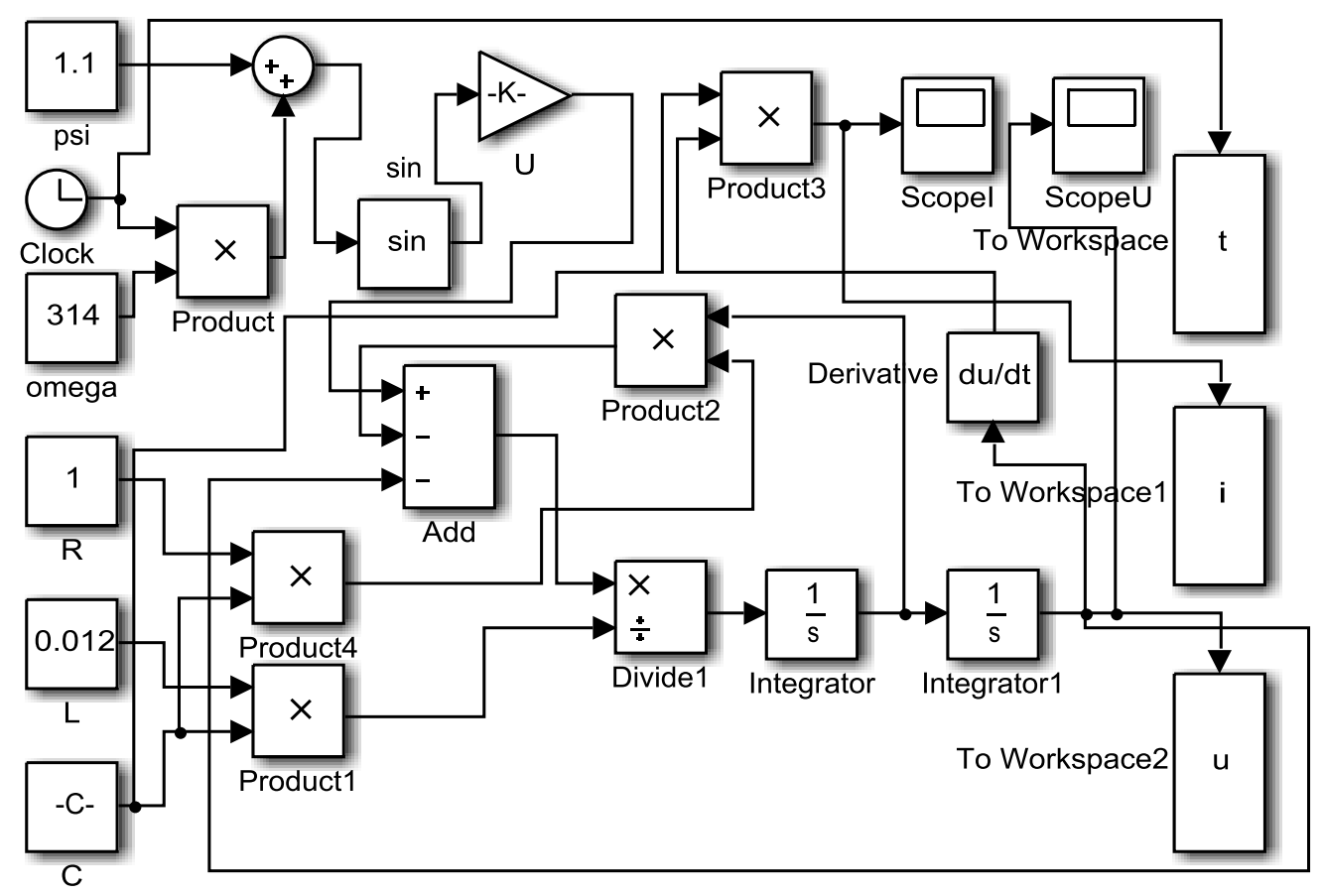

Fig. 6: Simulation Model for Current and Voltage Capacitor

The model integrates the differential equation (1) and allows tracing the forms of voltage and current variation regardless of operating regime. It was conceived to allow plotting the current and voltage diagrams for any value of 
circuit's parameters, which are input parameters for this model. The output forms of the model can be plotted by scopes or can be saved in workspace for further processing.

For the set of values corresponding to the oscillating regime are obtained the diagrams from Fig.7 and Fig.8:

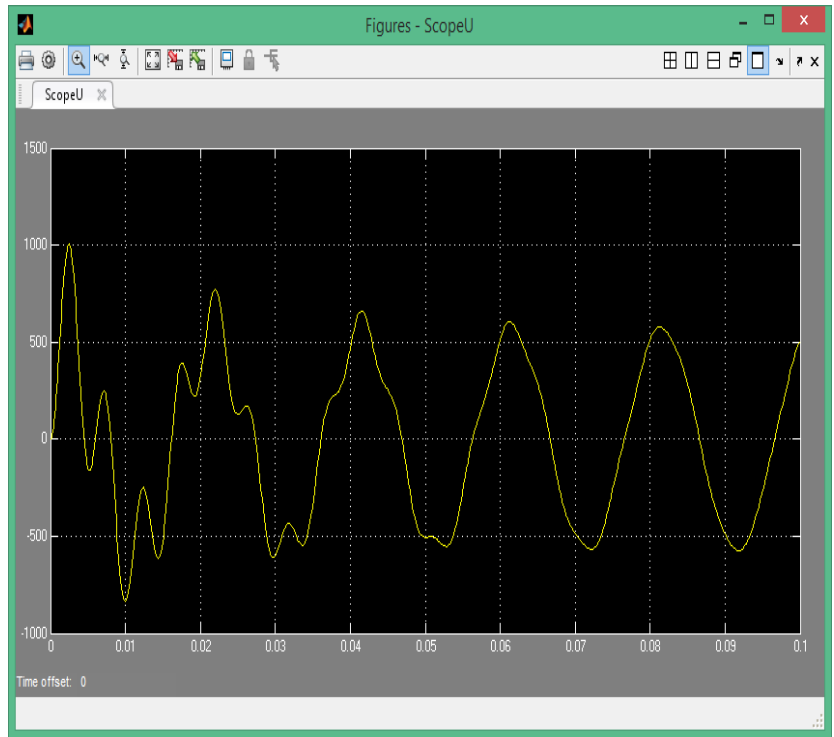

Fig. 7: Capacitor Voltage Diagram in the Oscillating Regime

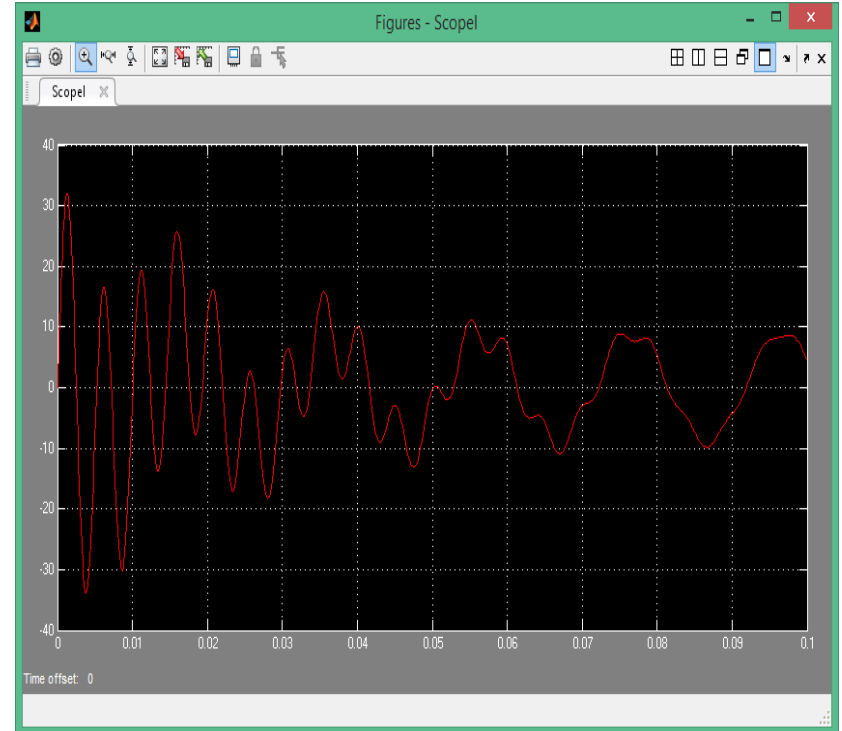

Fig. 8: Capacitor Current Diagram in the Oscillating Regime

The flowcharts of Fig. 7 and Fig. 8 were plotted for the same values of electrical parameters that the diagrams from Fig. 2 and Fig.3. It can be seen that the two sets of diagrams render identical dependences.

If in numerical simulation from Fig. 6 are given parameters which correspond to the a-periodic regime, it can obtain the variation forms specific for this regime:

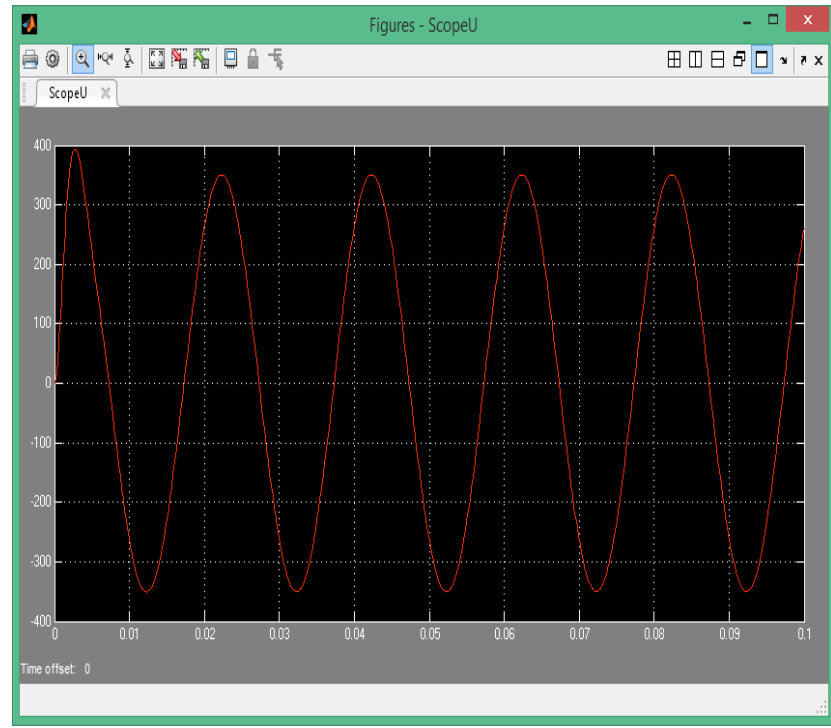

Fig. 9: Capacitor Voltage Diagram in the A-Periodic Regime
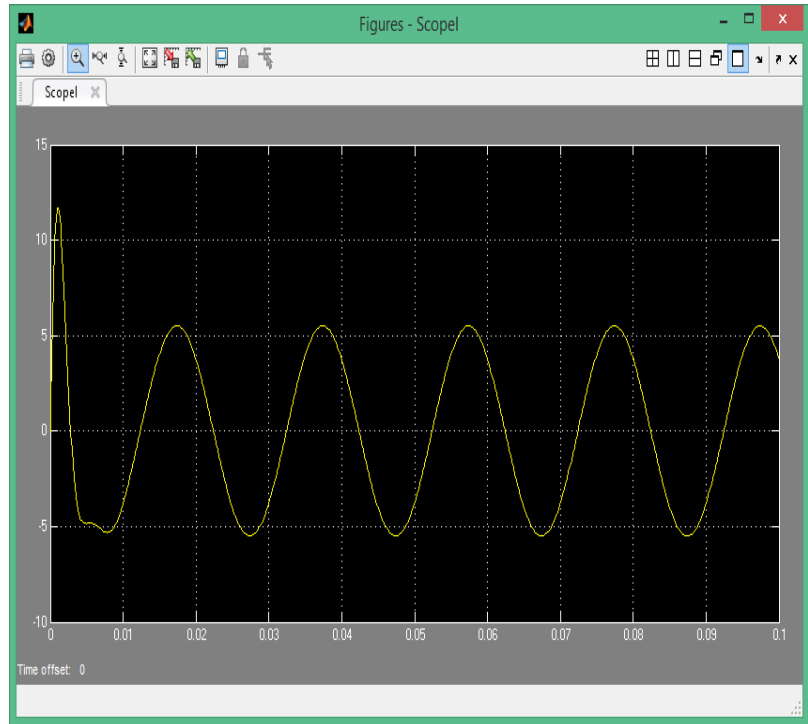

Fig. 10: Capacitor Current Diagram in the A-Periodic Regime

In Fig.9 was plotted the capacitor voltage diagram in the-periodic regime. It can see a voltage peak at the started of transitory regime and a while depreciation of these peaks. The diagram from Fig.10 shows a over current peak in the beginning of process in the-periodic regime.

\section{Experimental determination of the variation forms for voltage and current}

For experimental confirmation of these results, we used a data-acquisition system produced by the company National Instruments, NI USB-type 6003. Graphical environment used is the Labview software. The schema of the data acquisition in Labview is shown in Fig. 11, and the electrical scheme used is that of Fig. 12. Inductive-capacitive circuit is connected to the mains voltage via a contactor alternative $\mathrm{C}$, and input voltage levels in DAQ are obtained by resistive dividers. How to measure the differential is chosen. 


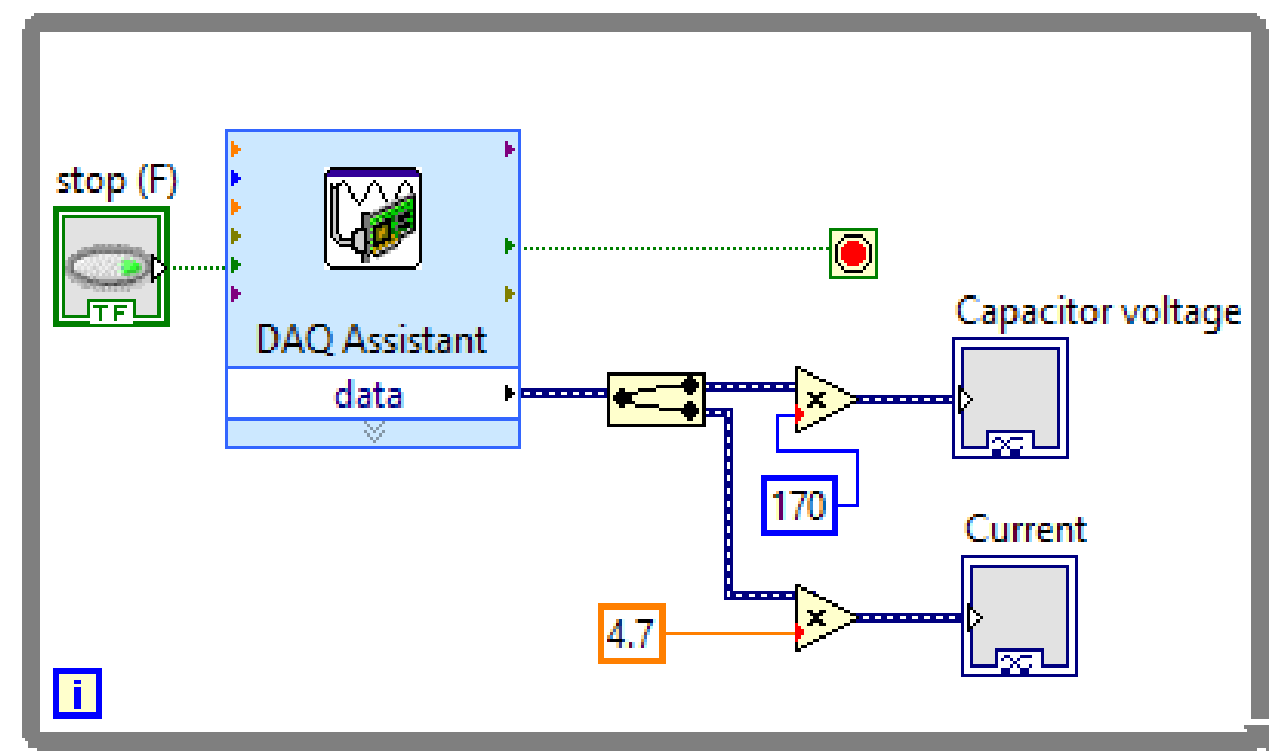

Fig. 11: Labview Diagram of the Process

Numeric constants included in Fig. 11 are correlated with the values of the resistors R0, i0, R R1 and Ri1 forming the two voltage dividers. To eliminate the risk to connect directly the phase voltage alternatives to the DAQ software have symmetrical voltage dividers used, the analog input of the measuring system is connected in parallel with the median flowing. For the protection of the analog inputs to the eventual DAQ inductors, diodes were used Zenner DZ.

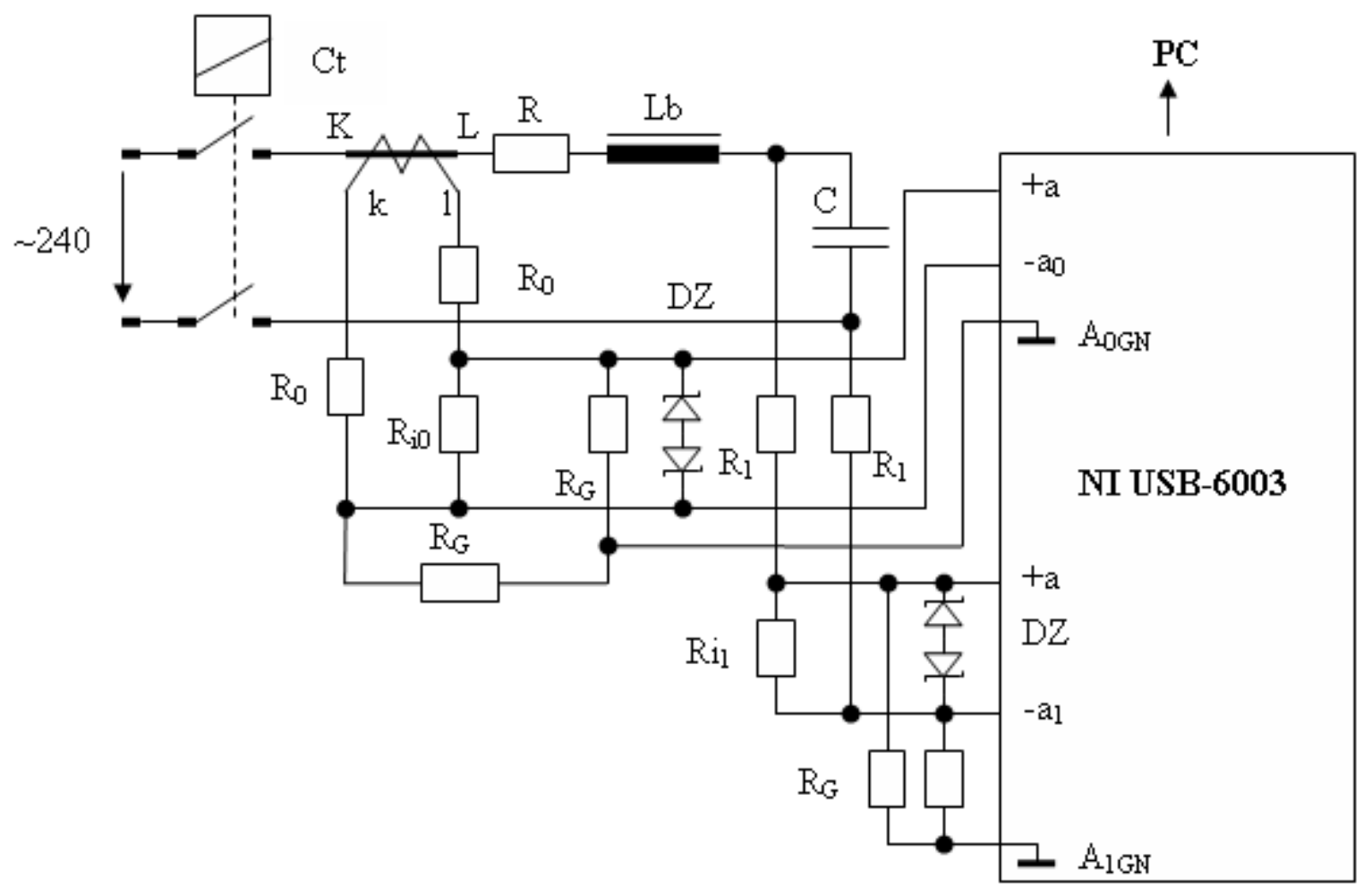

Fig. 12: Wiring Diagram of Installation of Measurement

The following measurements were obtained the following diagrams' variation of the voltage at the terminals of the capacitor and the current in the circuit. 


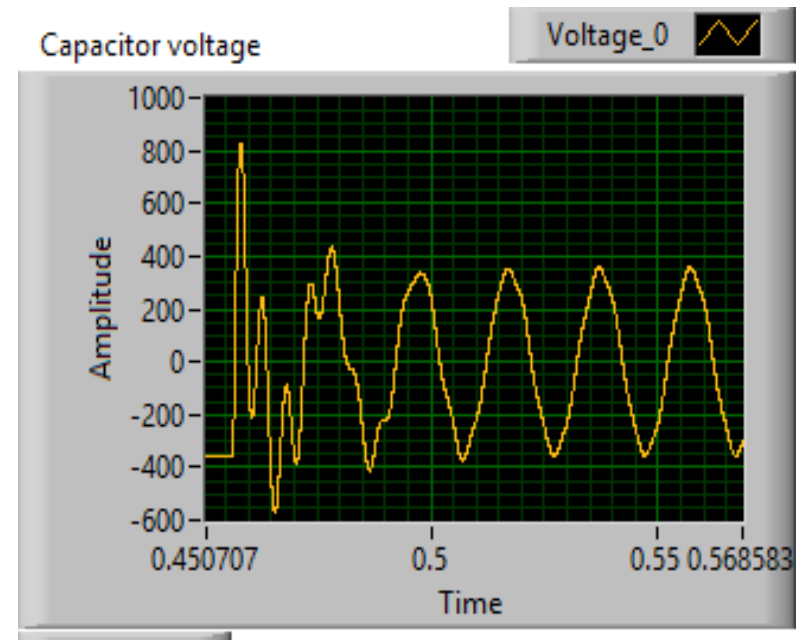

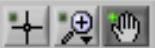

Fig. 13: Variation in Voltage on the Capacitor in the Oscillating Regime
Current

Voltage_1

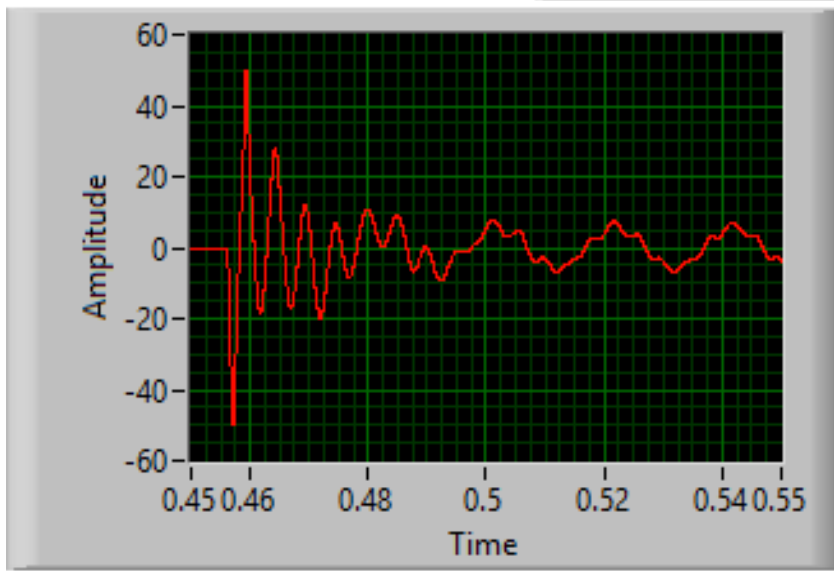

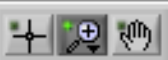

Fig. 14: The Current Variation in the Oscillating Circuit

For oscillatory regime with the parameter values for which the circuit has been obtained the previous diagrams (Fig. 2 , Fig. 3, Fig. 7, Fig. 8), resulting in Fig. 13 and Fig. 14 diagrams.

For the corresponding values for aperiodic arrangements (it increased the value of the resistance of the circuit $15 \Omega$ ), diagrams have been obtained:

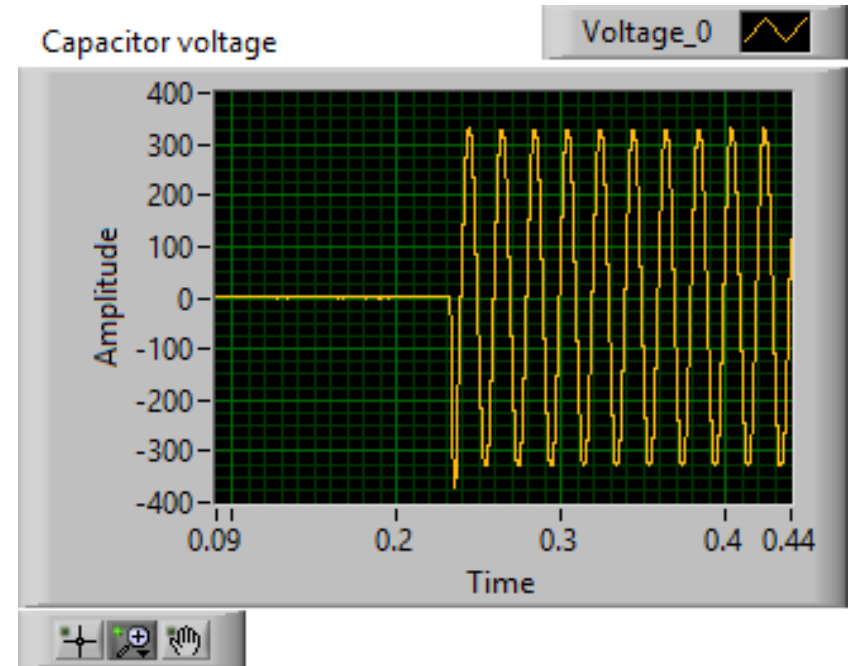

Fig. 15: Variation in Voltage on the Capacitor in Aperiodic
Current

Voltage_1

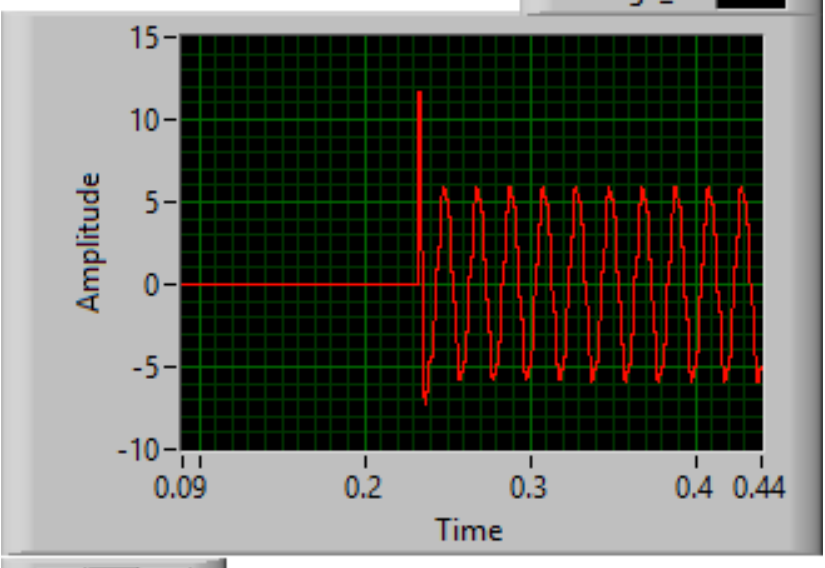

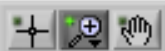

Fig. 16: The Current Variation in the Aperiodic Circuit Arrangements

\section{Conclusion}

All three methods presented for study the transitory phenomena which appear at a connecting capacitor banks to an AC power source, lead to the same conclusions. The variation forms of electrical parameters are identical in the first two cases. In the last situation, the results are very similar with the theoretical approach, which confirms that these methods are correct.

The first case presented, which is based on MATLAB programming space, is more complicated, because it involves solving the differential equation (1), finding solutions in every regime and creating programs for each situation: two programs for voltage and current in the oscillating mode and two programs for these parameters in the aperiodic regime. The second method presented simplifies this problem because it does not require knowledge of mathematics needed to solve equation (1). Based on this equation was developed a Simulink model that integrates a second-order differential equation. This model is unique because it leads to getting forms for voltage and current variation in both regimes, depending on the values of circuit parameters.

The experimental method is based on the acquisition of data leads to very closely resemble the diagrams obtained a theoretical way.

The most dangerous regime is the oscillating regime, and this is the most common regime which we can in practice the power-supply voltage of AC electric motors what includes the starting capacitor. The regime most frequently is the oscillating, considering that the resistance of the connecting wires is small. In this case, oscillating overvoltage may occur that need to be taken into account when sizing the systems. The value of these voltages depends on the connecting 
moment, which is the initial phase of the AC voltage. The design and sizing of these circuits must take into account the surge peaks that occur immediately after signing in and, which may endanger the internal insulation of the equipment. Overcurrent peaks in oscillating mode can lead to the prosecution of any protective relays on the circuit.

The connecting of capacitor's banks as a power source, at low voltage, can be made directly without dumping resistance (oscillatory regime). The frequency of current oscillations at connecting is approximate one kHz. This can take place at low voltage for capacitor banks to $25 \mathrm{kVAr}$.

It is important that the electric charge on the capacitor which is connected to be initially zero. Otherwise high value over current may occur in the after connecting moment.

We have to mention that these developed models can be used to generate explicit dependence for every real value of the circuit parameters.

\section{References}

[1] $* * *$ Software Matlab 2014a.

[2] $* * *$ Software LabView 2014

[3] Cristina Gabriela Saracin, Instalatii electrice, Editura MatrixRom, Bucuresti, 2008.

[4] Hortopan Ghe., Aparate electrice, E.D.P., Bucure ${ }^{\circ}$ ti, 1980.

[5] Horgos, M. ET all "Aspects of voltage dips, causes of production and their effect on consumers", Proceedings of the International Conference on ENERGY and ENVIRONME TECHNOLOGIES and EQUIPMENT (EEETE '10) - SPONSOR and ORGANIZER: Facultatea IMST, Universitatea Politehnica, Bucharest, Romania Published by WSEAS Press ISSN: 1790-5095 ISBN: 978-960-474-181-6, pag. 41 - 45.

[6] Nicolae Golovanov, s.a, Consumatori de energie electrica. Materiale. Masurari. Aparate. Instalatii, Editura AGIR, Bucuresti, 2009.

[7] Marin Ghinea, Virgiliu Firteanu, MATLAB calcul numeric- grafica-aplicatii, Editura Teora, Bucuresti, 2000.

[8] Niculescu, T., Analiza circuitelor electrice prin simulare in spapiul, MATLAB, Editura Focus, Petro ${ }^{\circ}$ ani, 2006.

[9] Niculescu, T. Technology and Engineering Applications of Simulink, Chapter 2: Study of Inductive-Capacitive Series Circuits Using the Simulink Software Package, ISBN 978-953-51-0635-7, Hard cover, Publisher: InTech, Published: May 23, 2012 under CC BY 3.0 license, in subject Technology.

[10] NICULESCU T. "Transitory phenomena in capacitive circuits connected to a AC source", Proceedings of the 4 th International Conference on Circuits, Systems, Control, Signals (CSCS'13 and the 1st International Conference on Electronics and Electrical Engineering (ELEL '13), Valencia, Spania August 2013, ISBN: 978-960-474-321-6, pp: 162-166.

[11] M.D. Marcu, F.G. Popescu, T. Niculescu, L. Pana, A.D. Handra, ,Simulation of power active filter using instantaneous reactive power theory”. Harmonics and Quality of Power (ICHQP), 2014 IEEE 16th International Conference, Bucharest, Romania, 25-28 May 2014, DOI: 10.1109/ICHQP.2014.6842783, Publisher: IEEE, pp: 581 - 585, http://dx.doi.org/10.1109/ICHQP.2014.6842783.

[12] T. Niculescu, M.D. Marcu, L. Panã, F.G. Popescu, "Sizing group of the extinguishing electric arc in DC hybrid breaker, one stage". Proceedings of the 15th International Conference on Automatic Control, Modelling \& Simulation (ACMOS '13), Brasov, Romania, June 1-3, 2013, pp: 37-41, http://www.wseas.us/e-library/conferences/2013/Brasov/ACMOS/ACMOS-04.pdf

[13] M. D. Marcu, F. Popescu, L. B. Samoila, "Modeling and Simuling Power Active Filter Using Method of Generalized Reactive Power Theory", Proceedings of IEEE International Conference on Computer Science and Automation Engineering, vol. 2, 10-12 June, 2011, Shanghai, China, IEEE Press, IEEE Catalog Number CFP1138L-PRT, pp: 213-218, http://ieeexplore.ieee.org/xpl/freeabs_all.jsp?arnumber=5952456

[14] Pãsculescu D, Niculescu T., Panã L. "Uses of Matlab software to size intrinsic safety barriers of the electric equipment intended for use in atmospheres with explosion hazard" Proceedings of the International Conference on ENERGY and ENVIRONME TECHNOLOGIES and EQUIPMENT (EEETE '10), SPONSOR and ORGANIZER: Facultatea IMST, Universitatea Politehnica, Bucharest, Romania Published by WSEAS Press ISSN: 1790-5095 ISBN: 978-960-474-181-6, pp: $17-21$.

[15] Simona Halunga-Fratu, Octavian Fratu, Simularea sistemelor de transmisie analogice si digitale folosind mediul MATLAB/SIMULINK, Editura MatrixRom, Bucuresti, 2004.

[16] Surianu, F.D., Retele electrice industriale, Editura Orizonturi Universitare, Timisoara,1999.

[17] Tiberiu Tudorache, Medii de calcul in ingineria electrica MATLAB, Editura MatrixRom, Bucuresti 2006.

[18] T. Tudorache, Medii de calcul în ingineria electricã, Editura MatrixRom, Bucuresti 2006.

[19] T. Niculescu, D. Pasculescu, L. Pana, "Study of the operating states of intrinsic safety barriers of the electric equipment intended for use in atmospheres with explosion hazard", Main Page of the Journal WSEAS TRANSACTIONS on CIRCUITS and SYSTEMS, Volum 9/2010, ISSN: 1109-2734, pp: 430-439.

[20] T. Niculescu, M. Niculescu, "The study of fundamental electrical circuits transitory phenomena using MATLAB software", Simpozion international multidiscilplinar UNIVERSITARIA SIMPRO 2010, Electrical Engineering and Energetics System Control, Applied Informatics and Computer Engineering, Editura Universitas Petrosani, octombrie 2010, pp: 31-34. 